\title{
Pedagogical knowledge in English language teaching: A lifelong-learning, complex-system perspective
}

Babak Dadvand (D) and Foad Behzadpoor

\section{How to cite this article}

Dadvand, B. and Behzadpoor, F. (2020) 'Pedagogical knowledge in English language teaching: A lifelong-learning, complex-system perspective'. London Review of Education, 18 (1): 107-125. https://doi.org/10.18546/LRE.18.1.08

Submission date: 22 January 2019

Acceptance date: 12 September 2019

Publication date: 1 March 2020

\section{Peer review}

This article has been peer reviewed through the journal's standard double-blind peer review, where both the reviewers and authors are anonymized during review.

\section{Copyright}

CCopyright 2020 Dadvand and Behzadpoor. This is an Open Access article distributed under the terms of the Creative Commons Attribution Licence (CC BY) 4.0 https://creativecommons.org/licenses/by/4.0/, which permits unrestricted use, distribution and reproduction in any medium, provided the original author and source are credited.

\section{Open access}

London Review of Education is a peer-reviewed open-access journal. 


\title{
Pedagogical knowledge in English language teaching: A lifelong-learning, complex-system perspective
}

\author{
Babak Dadvand* - University of Melbourne, Australia \\ Foad Behzadpoor - Azad University, West Tehran Branch, Iran
}

\begin{abstract}
Pedagogical knowledge has been the subject of theoretical and empirical studies. However, no research has so far integrated the existing scholarship with data to develop and validate a framework for pedagogical knowledge in English language teaching informed by lifelong-learning, complex-system perspectives. In the absence of such research, we used a mixed method research design through a systematic review of the literature, semi-structured interviews with experienced teachers $(\mathrm{N}=10)$ and teacher educators $(\mathrm{N}=10)$, as well as a survey of 336 practising teachers in Iran to: (1) develop a framework for pedagogical knowledge; and (2) validate this framework by designing a self-assessment questionnaire for pedagogical knowledge. Our analyses yielded a nine-component model that included: knowledge of subject matter; knowledge of teaching; knowledge of students; knowledge of classroom management; knowledge of educational context; knowledge of democracy, equity and diversity; knowledge of tests/exams; knowledge of learning; and knowledge of (professional) self. Within this nine-factor framework, each component of pedagogical knowledge consists of a number of subcomponents. The proposed framework highlights the multidimensionality and complexity of pedagogical knowledge, and the mutually constitutive relationships among different knowledge domains.
\end{abstract}

Keywords: complex system, conceptual framework, lifelong learning, pedagogical knowledge

\section{Introduction}

Despite substantial research on teaching over the past few decades, studies of teaching remain largely patchy and disjointed, leading to what Cochran-Smith and Villegas (2015: 8) have described as a 'sprawling and uneven field'. Strands of teaching and teacher education research have traditionally examined discrete elements such as pedagogical knowledge, pedagogical knowledge acquisition, pedagogical knowledge development and professional learning, often in the absence of a broader agenda that can help connect the siloed body of work in these areas of interest. Teaching and teacher education research has also been slow in utilizing the rich and growing body of scholarship that explores the complex and lifelong processes involved in learning, including in learning to teach. This has resulted in often reductionist views about what teaching, teaching knowledge and learning to teach entails.

This article synthesizes bodies of work in studies of teaching to bridge the boundaries between research on theories of learning to teach as a lifelong process and 
conceptualizations of pedagogical knowledge as a complex system. In so doing, we seek to fill a theoretical lacuna relating to the problem of 'construct under-examination' in teacher cognition research (Burns et al., 2015). While pedagogical knowledge has been the subject of studies, the construct still remains in need of theoretical development, analytic clarification and empirical examination (Loewenberg Ball et al., 2008). No research has so far offered an integrative account of pedagogical knowledge informed by lifelong-learning and complex-system perspectives. To address this gap, we draw on the existing literature and collected data to: (1) develop a conceptual framework for pedagogical knowledge; and (2) assess the construct validity of this framework by analysing data gathered through a survey of 336 practising teachers. Our model development and validation follow three interrelated stages. First, we conceptualize 'pedagogical knowledge' using lifelong-learning, complex-system perspectives. Then, we draw upon our conceptualization to identify the relevant literature and propose a tentative framework for pedagogical knowledge. Finally, we complement the framework with collected data and use it as a basis for model validation. Underpinning our conceptualization and model development effort is the premise that pedagogical knowledge is complex, context-responsive and evolves over time. Such an understanding helps acknowledge the fluid and ever-evolving nature of pedagogical knowledge in teaching. It also helps highlight the active, creative and constructive role that teachers play in the formation of their pedagogical knowledge through formal/informal learning opportunities, professional development and reflective practices.

A conceptualization of pedagogical knowledge along the lines that we have delineated above requires us to interrogate some of the categorical assumptions that are often made about knowledge in teacher education literature. This involves moving beyond the familiar dichotomies of knowledge as theories, knowledge as beliefs and knowledge as abilities (Woods and Çakır, 2011). Instead, pedagogical knowledge should be viewed as an integrative concept 'summarizing a large variety of cognitions, from conscious and well-balanced opinions to unconscious and unreflected intuitions' (Verloop et al., 2001: 446). This, in turn, leads to considerations of ontological, epistemological and methodological questions relating to articulated, embodied and/ or enacted forms of knowledge in teaching, and the ways in which such knowledge can be best brought together and mapped conceptually.

There are two main advantages in adopting a complex-system, lifelong-learning approach to pedagogical knowledge. First, complex-system theory and lifelonglearning perspectives can deepen our understanding of knowledge as a dynamic construct with multiple and mutually constitutive dimensions that remain in an everevolving state of becoming. Within a complex-system, lifelong-learning framework, all forms of articulated, embodied and enacted knowledge become inextricably intertwined and together constitute the totality of teachers' knowledge base. This can be particularly useful in reducing some of the existing complexities around the meaning(s) of pedagogical knowledge which, as Borg (2003) has suggested, are partly caused by the assemblage of terms and concepts in this area of teacher education research. Defined through a complex-system, lifelong-learning framework, pedagogical knowledge cross-cuts the analytical boundaries drawn among theoretical, personal and practical forms of knowledge. 


\section{Pedagogical knowledge: A complex-system, lifelong-learning perspective}

Discussions of teaching underwent a substantial shift during the late 1970s and early 1980s. This period marks the end of what is referred to as the process-product paradigm of research on teaching. With their root in positivism and behavioural psychology (Johnson, 2009), process-product studies helped capture observable dimensions of teaching. However, these studies failed to account for the judgements, reasonings and decision-making processes that teachers undertake in their practices. The inadequacy to explain the hidden and cognitive aspects of teaching ultimately led to the demise of the process-product research. Studies of teaching took a socio-cognitive turn and brought issues of context and cognition to the centre stage of teaching research. Subsequently, teachers came to be viewed as 'active, thinking decision-makers who make instructional decisions by drawing on complex practically-oriented, personalized, and context-sensitive networks of knowledge, thoughts, and beliefs' that evolve over time (Borg, 2003: 81).

Walberg's (1977) notion of teachers' mental lives marks a shift in thinking about teaching as a dynamic process of reasoning and decision-making. Within the emerging line of research, one area that became the subject of theoretical and empirical studies was teachers' knowledge base. Interest in understanding what constitutes knowledge in teaching, which threads through teacher education research until now, has given rise to numerous terms, each highlighting a particular dimension of teachers' knowledge. Among the multiplicity of terms, one can refer to practical knowledge (Elbaz, 1983), personal practical knowledge (Clandinin, 1986; Golombek, 1998), pedagogical content knowledge (Shulman, 1986), pedagogical maxims (Richards, 1996) and more recently pedagogical knowledge base (Gatbonton, 2000; Mullock, 2006).

Despite the growing body of scholarship on pedagogical knowledge, part of the limitations of existing research in teaching to date is the way in which pedagogical knowledge is conceptualized either as a discrete construct with clear-cut boundaries or as a finished product that remains uniform across time, space and social context. This is partly due to outcome-orientated and universal tendencies in conceptualizations of knowledge. In the absence of an integrative approach that examines how teachers' personal biographies may interact with the institutional, social, cultural and political factors to mediate their knowledge, we find Buehl and Fives's (2016) definition of 'epistemic cognition' in teacher learning and praxis a more conducive way of looking at pedagogical knowledge and its development. Epistemic cognition is a processorientated way of thinking about teacher learning and knowledge, and considers a variety of factors, including the task at hand, teachers' domain of experience, prior knowledge and existing beliefs, alongside practical experiences.

Understanding teachers' cognitions, Burns et al. (2015: 597) maintain, 'as situated, dynamic, mediated, and inherently complex, shifts us toward a complex, chaotic systems ontology'. Complexity theory has been increasingly drawn upon in education literature to provide a more nuanced explanation of the interplay between various factors impacting on teachers' work and the interactive cognitions that emerge from working in a diversity of contexts. Kiss (2012) maintains that complex systems have characteristics such as sensitivity to initial conditioning, unpredictability, nested structures, non-hierarchic network systems, use of feedback loops and self-organization. A complex-system approach has been used to highlight teacher cognition as dynamic and co-adaptive systems (Feryok, 2010) that are contingent upon interactions between 
belief systems, context and practices (Zheng, 2013, 2015) and that mediate teacher learning and professional development (Opfer and Pedder, 2011).

A second, and related, limitation of current conceptualizations is the way in which pedagogical knowledge is often perceived as a construct that remains uniform across the life-course. This is reflected in research that provides snapshots of knowledge with little attention to the processes of knowledge development. More recently, there has been greater acknowledgment of the multilevel and multidimensional nature of teacher learning, which involves cognitive, emotional and motivational aspects of learning to teach spread across teachers' personal and professional lives (Korthagen, 2017). Schwille et al. (2007) use the term 'continuum of teacher learning' to highlight the lifelong processes of learning to teach. Continuum of teacher learning implies a concern not only with formal teacher preparation, induction and professional development, but also with other informal influences on how and what teachers learn.

The learning journey towards becoming a teacher starts with what Lortie (1975) describes as apprenticeship of observation, which refers to the influences on teachers' perceptions of effective pedagogies from their own years of schooling as students. Apprenticeship of observation is complemented by formal pre-service education that offers opportunities for structured learning believed to contribute to the acquisition of conceptual-theoretical knowledge about teaching (Watzke, 2007). Other phases in the continuum of teacher learning include induction and/or placement and continuing professional development opportunities, which are looser in arrangement and that can occur in less formal and structured ways through communities of practice, everyday interactions with colleagues and/or via reflective practices that help revisit long-held assumptions and beliefs.

The multiplicity of sources that contribute to teachers' learning prompts our attention to the ongoing and open-ended processes by which teachers develop their individual, self-directed modes of learning in response to the particularities of their life situations (Su et al., 2018). It is within this broad spectrum of lifelong learning to teach that teachers, as active and reflective practitioners, build their interactive cognition and develop, amend and revisit their pedagogical knowledge. Conceptualizations of pedagogical knowledge, therefore, need to account for the evidence base that points to the complexities and dynamics of pedagogical knowledge and the multilevel and multidimensional processes of learning to teach.

\section{Procedure}

Initial conceptualization is an important step in model development and helps set the parameters for the later stages (Jakeman et al., 2006). We therefore used the conceptual definition of knowledge delineated above as the starting point for developing a tentative framework that can map out the complex interconnections between different dimensions of the construct. We derived our definition of pedagogical knowledge from earlier work that points not only to the bodies of knowledge 'about the act of teaching, including goals, procedures, and strategies that form the basis for what teachers do in classroom' (Mullock, 2006: 48), but also to the accumulated knowledge about content, culture and political context (Akbari and Dadvand, 2014). The standard procedure for model development follows from conceptualization to the review of the literature (Dörnyei, 2003). To this end, we examined existing studies of pedagogical knowledge. Given that some aspects of pedagogical knowledge are specific to learning areas, we focused on the literature review on English language teaching. This was done by searching the archives of the education databases of ERIC, EBSCO, SAGE 
and Education Research Complete. The multidisciplinary databases of ScienceDirect and ProQuest, as well as the major academic journals, were also searched to ensure relevant studies were included in our literature review.

Eligibility criteria included both conceptual and empirical studies of teaching knowledge in the broader field of teacher education, and within the subfield of English language teaching. Inclusion criteria also included peer-reviewed articles, reports, policy documents, books and book chapters that were written in English on the topic. The following terms were used in the database search: 'pedagogical/teaching knowledge', 'knowledge base', 'teacher expertise', 'teacher cognition', 'pedagogical beliefs', 'teaching beliefs', 'teaching expertise', 'teaching effectiveness', 'lifelong learning in teaching', and 'complex system in teaching'. The broad initial inclusion criteria allowed for identifying a relatively large number of studies. A subsequent exclusion criterion was applied to remove studies that were either 'incomplete', followed 'ambiguous methodologies' or had little 'content relevance'. This led to a shortlist of 236 publications that dealt specifically with different dimensions of knowledge in teaching.

In the next step, the identified studies were analysed to map out the area(s) of pedagogical knowledge. These knowledge areas were then used to draw conceptual boundaries among the key domains of pedagogical knowledge. These conceptual boundaries later became the basis of a tentative ten-component framework. Within this tentative framework (see Table 1), each component of pedagogical knowledge contained a set of subcomponents that together constituted separate, yet interdependent, domains of pedagogical knowledge, including: knowledge of subject matter; knowledge of culture and cultural differences; knowledge of students; knowledge of learning; knowledge of teaching; knowledge of tests/exams; knowledge of classroom management; knowledge of educational context; knowledge of democracy, equity and diversity; and knowledge of professional self.

\section{Table 1: A tentative framework for pedagogical knowledge in teaching}

\begin{tabular}{lll}
\hline $\begin{array}{c}\text { Component of } \\
\text { knowledge }\end{array}$ & Subcomponent of knowledge & References (examples) \\
\hline & English grammar & \\
& Grammatical terminology & \\
& English vocabulary & \\
& English morphology & \\
& English idiomatic expressions & \\
& English pronunciation & \\
& English intonation patterns & Andrews and Svalberg, 2016; \\
& Dialect/accent varieties in English & Svalberg, 2015; \\
& Reading comprehension & Farrell and Lim, 2005; \\
& Reading strategies & Baker, 2014; \\
Knowledge of & English writing & \\
subject matter & Writing techniques 2010 \\
& English speaking & \\
& Speaking strategies & \\
& Listening comprehension & \\
& Listening comprehension strategies & \\
& Students' first language & \\
& First and second language & \\
& similarities/differences & \\
&
\end{tabular}




\begin{tabular}{|c|c|c|}
\hline $\begin{array}{l}\text { Component of } \\
\text { knowledge }\end{array}$ & Subcomponent of knowledge & References (examples) \\
\hline $\begin{array}{l}\text { Knowledge of } \\
\text { culture and cultural } \\
\text { differences }\end{array}$ & $\begin{array}{l}\text { Local culture } \\
\text { English culture } \\
\text { L1 and L2 cultural similarities/ } \\
\text { differences }\end{array}$ & $\begin{array}{l}\text { McKay, 2003; } \\
\text { Akbari and Tajik, } 2012\end{array}$ \\
\hline $\begin{array}{l}\text { Knowledge of } \\
\text { students }\end{array}$ & $\begin{array}{l}\text { Attributes of learners } \\
\text { Learners' backgrounds } \\
\text { Students' language skills and } \\
\text { abilities } \\
\text { Students' interests and motivation } \\
\text { Affective/appropriate student- } \\
\text { teacher relationship }\end{array}$ & $\begin{array}{l}\text { Bauml, 2009; } \\
\text { Mulcahy, } 2012\end{array}$ \\
\hline $\begin{array}{l}\text { Knowledge of } \\
\text { (second language) } \\
\text { learning }\end{array}$ & $\begin{array}{l}\text { The processes involved in language } \\
\text { learning } \\
\text { How to facilitate learning } \\
\text { Students' task involvement, } \\
\text { progress and difficulties } \\
\text { How to deal with students' errors }\end{array}$ & $\begin{array}{l}\text { Reeves, 2009; } \\
\text { Mori, 2011; } \\
\text { Yoshida, } 2010\end{array}$ \\
\hline $\begin{array}{l}\text { Knowledge of } \\
\text { (second language) } \\
\text { teaching }\end{array}$ & $\begin{array}{l}\text { Educational goals and objectives } \\
\text { Teaching approaches } \\
\text { Teaching techniques } \\
\text { Teaching methods } \\
\text { Lesson planning } \\
\text { Knowledge base for technology }\end{array}$ & $\begin{array}{l}\text { Akbari and Dadvand, 2011; } \\
\text { Fisher, 2009; } \\
\text { Liu et al., } 2017\end{array}$ \\
\hline $\begin{array}{l}\text { Knowledge of } \\
\text { assessment/testing }\end{array}$ & $\begin{array}{l}\text { Theoretical basis of language tests } \\
\text { and assessment procedures } \\
\text { Knowledge base for test/exam } \\
\text { design } \\
\text { Knowledge base for test/exam } \\
\text { grading } \\
\text { Different methods for assessing } \\
\text { progress and achievement } \\
\text { Exam/test wash-back }\end{array}$ & $\begin{array}{l}\text { Inbar-Lourie, 2008; McNamara, } \\
2005\end{array}$ \\
\hline $\begin{array}{l}\text { Knowledge } \\
\text { of classroom } \\
\text { management }\end{array}$ & $\begin{array}{l}\text { Classroom time management } \\
\text { Classroom order } \\
\text { Instructional management }\end{array}$ & $\begin{array}{l}\text { Darling-Hammond and } \\
\text { Bransford, 2005; } \\
\text { Osam and Balbay, } 2004\end{array}$ \\
\hline $\begin{array}{l}\text { Knowledge of } \\
\text { educational context }\end{array}$ & $\begin{array}{l}\text { Curriculum content and curriculum } \\
\text { goals } \\
\text { Institution/school policies } \\
\text { Instructional materials } \\
\text { Available teaching/learning } \\
\text { resources }\end{array}$ & $\begin{array}{l}\text { Ben-Peretz, 2011; } \\
\text { Tsang, } 2004\end{array}$ \\
\hline $\begin{array}{l}\text { Knowledge of } \\
\text { democracy, equity } \\
\text { and diversity }\end{array}$ & $\begin{array}{l}\text { Sociopolitical/cultural context of } \\
\text { instruction } \\
\text { Discrimination and marginalization } \\
\text { The power dynamics associated } \\
\text { with language use }\end{array}$ & $\begin{array}{l}\text { Hayes, 2010; } \\
\text { Myers, } 2009\end{array}$ \\
\hline $\begin{array}{l}\text { Knowledge of } \\
\text { (professional) self }\end{array}$ & $\begin{array}{l}\text { (Professional) self } \\
\text { Professional relations } \\
\text { Knowledge base for professional } \\
\text { development }\end{array}$ & $\begin{array}{l}\text { Hillier, 2005; } \\
\text { Pollard, } 2005\end{array}$ \\
\hline
\end{tabular}




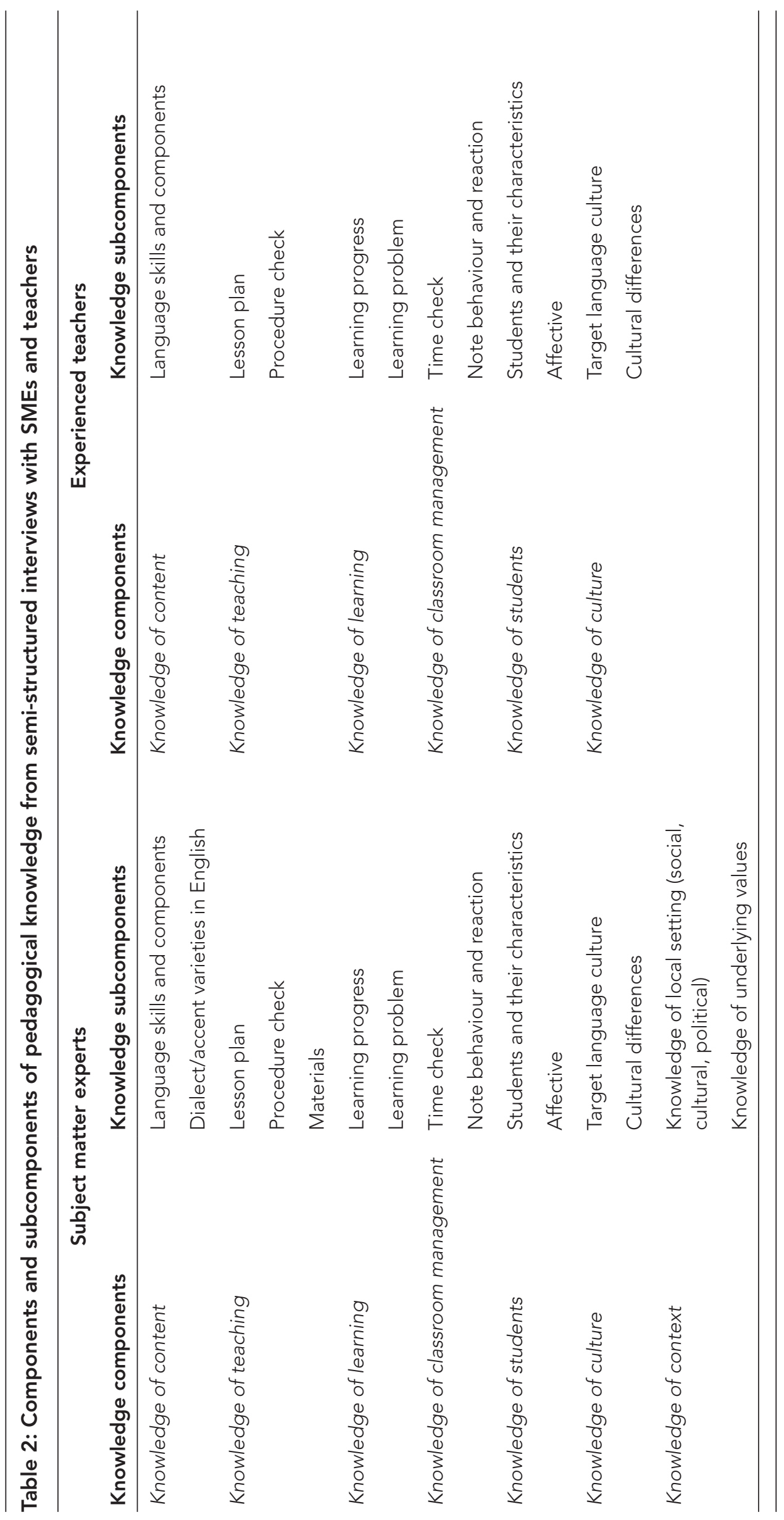


Qualitative data were collected in an effort to review, complement and consolidate the structure of the initial framework. We conducted semi-structured interviews with two groups of participants: ten experienced English teachers and ten subject matter experts (SMEs). These two participant groups were deemed suitable for their expert opinion and evaluative reflections on the initial conceptualization. First, ten experienced English language teachers, teaching in two private language institutes across Tehran, Iran, were invited to take part in semi-structured, reflective interviews using convenient sampling technique. These participants, seven males and three females, had a range of teaching experience from 5 to 12 years, and all had graduate degrees in English teaching. Ten SMEs were also invited to participate, using snowball sampling technique. These were university lecturers and teacher educators with the main responsibility of delivering undergraduate/graduate coursework and supervising practicum in teacher education programmes. Of these participants, six were male and four were female, with 4 to 11 years of teaching experience from four universities and institutes of higher education that provide master's of English language teaching in Tehran. Both experienced English teachers and SMEs were invited to take part in the study, and were informed about the aims of the research before participating in the interviews.

The semi-structured interviews with the experienced teachers and the SMEs lasted between 32 and 97 minutes. The interviews: (1) probed into the participants' perspectives regarding important areas of pedagogical knowledge for teachers; and (2) elicited their reflective feedback on the initial conceptualization of pedagogical knowledge. The interviews were transcribed and analysed to identify any additions to the components and subcomponents of knowledge. The analysis of the teachers' data pointed to six components of knowledge: knowledge of content, knowledge of teaching, knowledge of learning, knowledge of classroom management, knowledge of students, and knowledge of culture. The interview data from the SMEs pointed to seven components: knowledge of content, knowledge of teaching, knowledge of learning, knowledge of classroom management, knowledge of students, knowledge of culture, and knowledge of context. In both cases, each component of knowledge consisted of a number of subcomponents, summarized in Table 2. In the last stage of the model development phase, the components and subcomponents of pedagogical knowledge that emerged from the analyses of the interview data were triangulated with those of the tentative framework developed from the literature. Overall, this triangulation confirmed the structure of the initial model, but did not add any new elements to the framework. Therefore, we proceeded to model validation using the framework of pedagogical knowledge that had emerged from the review of the literature.

\section{Model validation}

A self-assessment questionnaire was developed in order to examine the construct validity of the framework. The questionnaire was piloted with a random sample of 40 teachers from two private language institutes in Tehran who were invited to participate in the research. Once the reliability of the questionnaire was established (Cronbach alpha coefficient: 0.91), we distributed 600 questionnaires to a random sample of practising English language teachers at different institutes, schools, and centres of higher education in Tehran and four other provinces across the country. Both face-to-face methods and emails were used to invite participants. The participants were informed of the purpose of the study, the right to voluntary participation and possible withdrawal, as well as the confidentiality/anonymity of their responses. Of the 
600 invited participants, 382 filled out and returned the questionnaire (a return rate of 64 per cent). Upon initial inspection, 46 questionnaires were discarded because they either had missing items or incomplete information. This left 336 questionnaires for model validation. Our model validation framework included three phases of exploratory data analysis (EDA), confirmatory data analysis (CDA) and model evaluation (Figure 1).

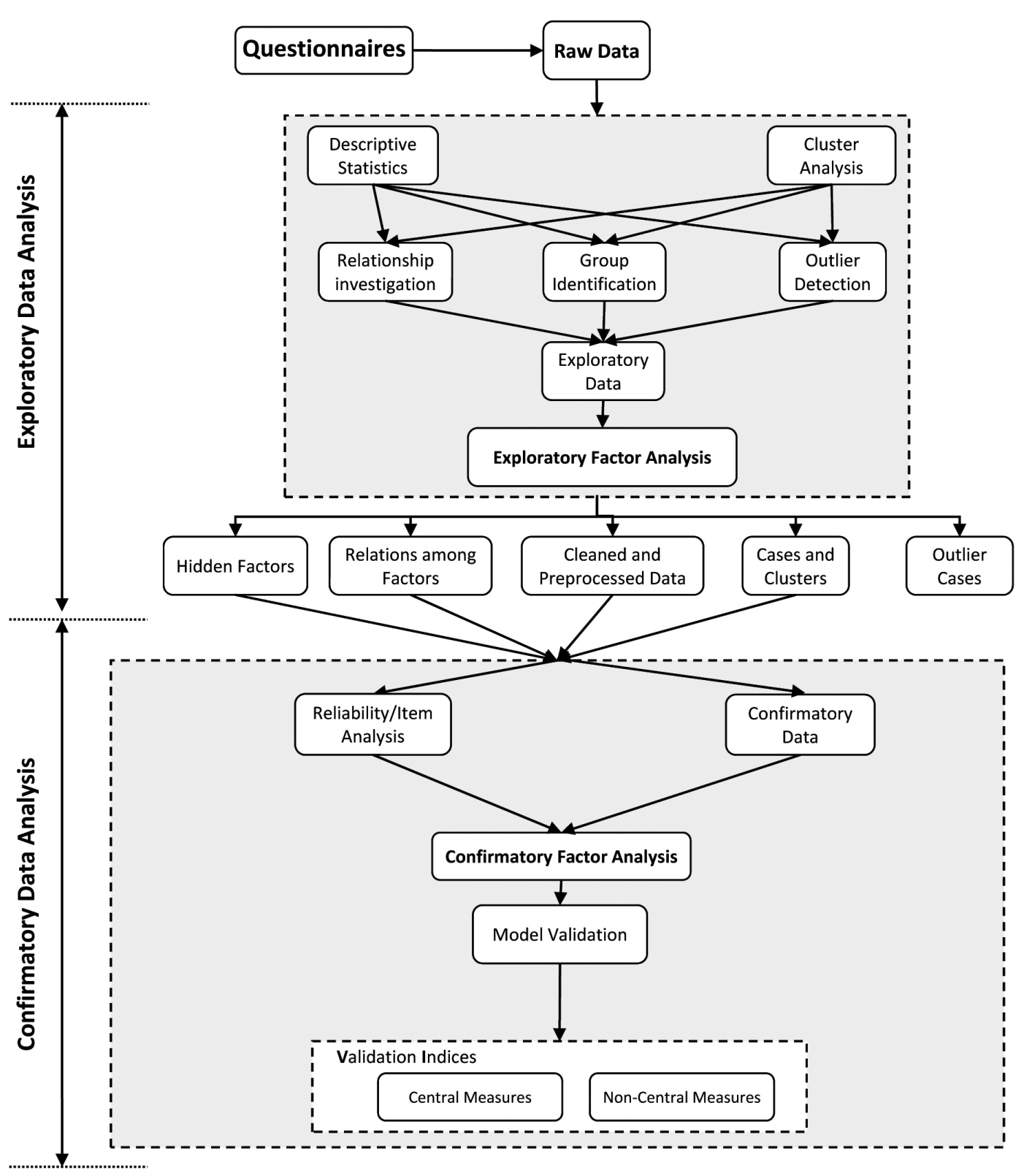

Figure 1: Three stages of EDA, CDA and model evaluation used in model validation

The SMEs were also consulted during the model validation phase. This helped us examine the conceptual integrity of the model at each stage of the analyses. Figure 2 shows the iterative process that was used during model validation. 


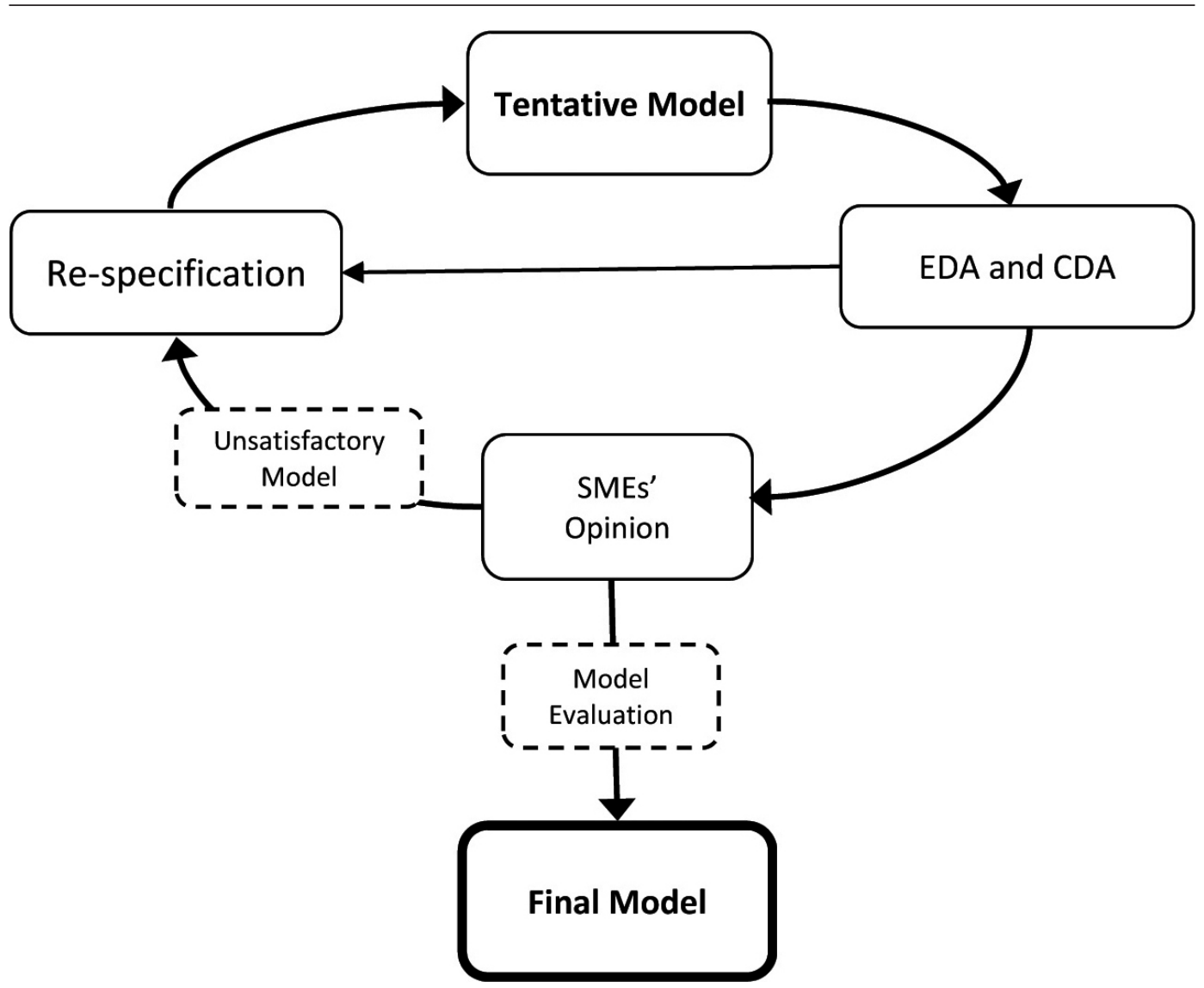

Figure 2: Iterative process of model validation

Prior to any analyses, Statistical Package for Social Sciences (SPSS, Version 17) was used to conduct reliability analysis on the 336 questionnaires (Cronbach's alpha coefficient: 0.84). Descriptive statistics did not indicate abnormality in the mean, standard deviation, and normality of distribution of the data. Then, cluster analysis and group identification analyses were conducted on the data to identify subgroups for the subsequent model exploration and confirmation. Ward's minimum variance method pointed to five groups with no outliers. The data, then, were grouped into five clusters using the K-means refinement. One-way analysis of variance (ANOVA) confirmed the reliability of data clustering showing significant mean difference among the clusters $(p<0.05)$. After data clustering, we divided the dataset into exploratory and confirmatory data with the ratio of 2:1 (Sharma, 1996): 236 participants with equal representation from the five clusters were assigned to the exploratory dataset, and the remaining participants became the confirmatory dataset.

\section{Exploratory data analysis (EDA)}

During the EDA phase, the exploratory data from the earlier clustering stage underwent principle component analysis (PCA) with varimax rotation to uncover the underlying constructs in the data (Shultz and Whitney, 2005). As a measure against multicollinearity, the determinant was calculated to be higher than 0.00001. Kaiser-Meyer-Olkin (KMO) measure of sampling adequacy (.816) and Bartlett's test of sphericity (.000) were both significant, indicating that the data were factorable. PCA with varimax rotation on the exploratory dataset gave way to nine factors with eigenvalues greater than one. These 
nine factors, which had minimum item-on-factor loadings of 0.35 , together accounted for 57 per cent of the variance in the data. Cattell's scree test of eigenvalues was also used to plot the number of factors supported by the data. The results confirmed the factor structure that emerged from PCA.

Consultation with SMEs confirmed the conceptual integrity of the PCA factor structure. In the emergent framework, knowledge of subject matter accounted for 17 per cent of the total variance, followed by knowledge of teaching (13 per cent). These were followed by knowledge of students ( 6 per cent); knowledge of classroom management (4 per cent); knowledge of educational context (4 per cent); knowledge of democracy, equity and diversity (4 per cent); knowledge of tests/exams (3 per cent); knowledge of language learning ( 3 per cent); and knowledge of professional self ( 3 per cent). It is worth noting that despite the overall correspondence of the PCA factor structure with the factor structure of the tentative model of pedagogical knowledge from the literature, there were differences between the two frameworks. First, knowledge of culture and cultural differences did not emerge as a separate factor from the EDA. The subcomponents of this knowledge all loaded on knowledge of students. In addition, knowledge of students' first language, and knowledge of first and second similarities/differences loaded on knowledge of students. Knowledge base for professional development was part of knowledge of professional self in the tentative model loaded on knowledge of teaching instead.

\section{Confirmatory data analysis}

The CDA phase started with reliability and item analysis on the emergent nine-factor framework of pedagogical knowledge from the EDA phase. Cronbach's alpha was used to estimate the variance for the factor structure that emerged from the EDA. Then, LISREL (Version 8.8) was used to conduct confirmatory factor analysis (CFA) on the confirmatory data, which helped empirically test the EDA factor structure (Sharma, 1996). During the CDA, the remaining 100 self-assessment questionnaires of the confirmatory data set underwent CFA. CFA verified the nine-factor model of pedagogical knowledge. The loadings between the indicators (subcomponents of knowledge) and the latent factors (component of knowledge), as well as the covariance among the factors, were all significant at $\alpha=0.001 \quad(p \leq 0.001)$. However, four subcomponents of knowledge did not load on their corresponding components in the analyses. These included knowledge of English culture, knowledge of instructional management, knowledge of curriculum and its objectives, and knowledge of available teaching/learning resources. The exclusion of these subcomponents gave way to a nine-factor model with 50 items. (See Figure 3 for the final self-assessment questionnaire.)

We consulted the SMEs about the conceptual integrity of the final model, especially the four items that were removed from the final framework. The SMEs still considered these four subcomponents as important constituents of language teachers' knowledge base. Our explanation for removing these subcomponents rests on our assumption that the other subcomponents of knowledge in the model already tap into the knowledge that these subcomponents addressed. With this explanation, and given the absence of sufficient empirical support for their inclusion, we removed these four items from the framework prior to the final phase of our model validation, namely the model evaluation phase. 
Dear respondent,

This questionnaire aims to measure your KNOWLEDGE about English Language Teaching (ELT). Each item is, thus, designed to examine one aspect of your professional knowledge as an English teacher in relation to your performance in classroom. Please answer the questions to the best of your knowledge by checking the box that best describes your state of teaching knowledge. Your thoughtful and candid responses are greatly appreciated.

Your information and responses will be kept confidential and will be used only for research purposes. Thank you very much in advance for your time and cooperation.

\section{Demographic Information}

\begin{tabular}{|c|c|c|c|}
\hline Email address: ....................... & $\begin{array}{l}\text { Gender: } \\
\square \text { Female } \\
\square \text { Male }\end{array}$ & Age: .... & Teaching experience (years): .... \\
\hline $\begin{array}{l}\text { Degree: } \\
\square \text { No degree } \quad \square \text { BA in English } \\
\square \text { Degree in other fields, please sp }\end{array}$ & \multicolumn{2}{|c|}{$\begin{array}{l}\square \mathrm{MA} \text { in English } \\
\text { cify: ................... }\end{array}$} & PhD in English \\
\hline
\end{tabular}

\section{The Questionnaire}

\begin{tabular}{|c|c|c|c|c|c|}
\hline Pedagogical Knowledge Base & 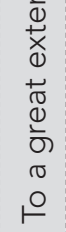 & $\frac{\frac{c}{U}}{\sum^{2}}$ & $\begin{array}{l}+\frac{\pi}{\sigma} \\
\frac{c}{3} \\
\bigotimes \\
\varepsilon \\
0 \\
\omega\end{array}$ & 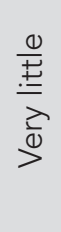 & $\begin{array}{l}\overline{\bar{\sigma}} \\
+ \\
+ \\
+ \\
+ \\
\end{array}$ \\
\hline $\begin{array}{l}\text { 1. I know the grammar rules of English language, for example its } \\
\text { various sentence structures, tenses, connectors, and articles. }\end{array}$ & $\square$ & $\square$ & $\square$ & $\square$ & $\square$ \\
\hline $\begin{array}{l}\text { 2. I know the grammatical terms needed to explain English grammar, } \\
\text { for example names of different tenses, clauses, and auxiliary verbs. }\end{array}$ & $\square$ & $\square$ & $\square$ & $\square$ & $\square$ \\
\hline $\begin{array}{l}\text { 3. I know a broad range of English vocabulary for referring to various } \\
\text { entities/objects, situations, and topics. }\end{array}$ & $\square$ & $\square$ & $\square$ & $\square$ & $\square$ \\
\hline $\begin{array}{l}\text { 4. I know English morphology, for example English word structure, } \\
\text { rules of word formation, and different parts of speech. }\end{array}$ & $\square$ & $\square$ & $\square$ & $\square$ & $\square$ \\
\hline $\begin{array}{l}\text { 5. I know the idiomatic expressions, common phrases and sayings of } \\
\text { English language. }\end{array}$ & $\square$ & $\square$ & $\square$ & $\square$ & $\square$ \\
\hline $\begin{array}{l}\text { 6. I know English phonology, that is how words are pronounced and } \\
\text { syllabically stressed in English. }\end{array}$ & $\square$ & $\square$ & $\square$ & $\square$ & $\square$ \\
\hline $\begin{array}{l}\text { 7. I know English intonation patterns, for example intonations } \\
\text { characteristic of questions, requests, and statements. }\end{array}$ & $\square$ & $\square$ & $\square$ & $\square$ & $\square$ \\
\hline $\begin{array}{l}\text { 8. I know the difference(s) among English dialects and accents, for } \\
\text { example American English, British English, Indian English, and African- } \\
\text { American English Vernacular. }\end{array}$ & $\square$ & $\square$ & $\square$ & $\square$ & $\square$ \\
\hline $\begin{array}{l}\text { 9. I can read English texts/passages from different genres (poetic, } \\
\text { fictional, informational, etc.), topics (news, sports, science, etc.), } \\
\text { difficulty levels (elementary, intermediate, advanced, etc.). }\end{array}$ & $\square$ & $\square$ & $\square$ & $\square$ & $\square$ \\
\hline $\begin{array}{l}\text { 10. I know what strategies facilitate reading comprehension, for } \\
\text { example skimming/scanning, activating background knowledge, } \\
\text { drawing inferences, and questioning the text. }\end{array}$ & $\square$ & $\square$ & $\square$ & $\square$ & $\square$ \\
\hline $\begin{array}{l}\text { 11. I can write in English, for example different types of essays } \\
\text { (descriptive, argumentative, narrative, etc.), formal/informal letters, } \\
\text { and notes and memos. }\end{array}$ & $\square$ & $\square$ & $\square$ & $\square$ & $\square$ \\
\hline $\begin{array}{l}\text { 12. I know the techniques that help the writing process/product, for } \\
\text { example pre-writing, drafting, revising, and editing. }\end{array}$ & $\square$ & $\square$ & $\square$ & $\square$ & $\square$ \\
\hline
\end{tabular}


Pedagogical Knowledge Base

13. I can speak English in different situations (formal vs. Informal) with different interlocutors (native vs. non-native), and around different topics (daily conversations, discussions, and explanations)

14. I know the strategies that facilitate speaking English, for example how to open, sustain and close formal and/or informal conversations, present ideas, and discuss topics.

15. I can understand English spoken with different accents/dialects in different formal/informal contexts (conversations, lectures, etc.), and about different topics.

16. I know the strategies that facilitate comprehension of spoken English, for example listening for the main idea, listening for details, predicting, and drawing inferences.

17. I know my students' first language, for example its grammatical rules, phonological features, and word formation processes.

18. I know the similarities and differences of my students' first language with English language, for example their grammatical, phonological, and morphological differences/similarities.

19. I know my students' local culture, for example their cultural norms, values and taboos, their shared beliefs/attitudes, and their accepted practices.

20. I know the similarities and differences of English culture with the local culture of my students.

21. I know the particular attributes of my students, for example their personality features, their emotional state, and their typical reactions/ behaviours.

22. I know about my students' life history and background, for example their family, cultural and religious experiences, and their ethnic/ language backgrounds.

23. I know my students' language abilities and their major learning strengths/weaknesses, for example their different language talents, and their learning skills/abilities.

24. I know what interests my students and keeps their motivation high in class, for example the topics they like (art, literature, sports, politics, etc.), and the activities that motivate them (role play, language games, etc.).

25. I know how to maintain positive affective relationship with my students, for example how to respond to their feelings and emotions, and how to build/maintain rapport with them.

26. I know how language learning takes place, for example through repetition, through explanation/analysis, and through use in real-life situations.

27. I know how to facilitate language learning for my students, for example through interaction/communication, repetition, and focus on form vs. focus on forms.

28. I know the level of my students' involvement in classroom activities, and their progress/difficulties during the lesson.

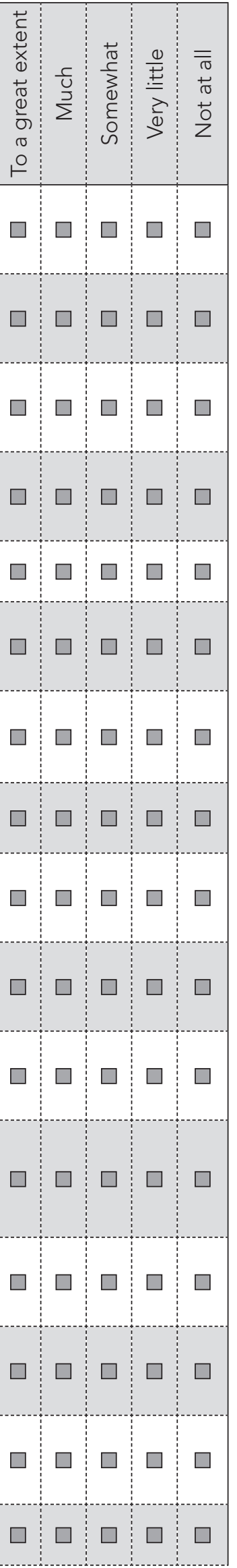


Pedagogical Knowledge Base

29. I know how to deal with my students' language errors/mistakes, for example through explicit/implicit feedback, peer correction, and self-correction.

30. I know my teaching goals and objectives, for example developing literacy skills, communicative skills, and critical thinking abilities.

31. I know how to use different teaching approaches in my classes, for example presentation, explanation, demonstration, and translation.

32. I know how to use different teaching techniques in my classes, for example brainstorming, language games, and question \& answer.

33. I know how to use a specific teaching method or combination of methods in my classes, for example grammar translation, communicative language teaching, and eclectic methods.

34. I know how to plan for my teaching, that is, how to select appropriate activities and arrange them in the order that they should unfold in class.

35. I know how to use multimedia (for example, audio-visual equipment) and technology (for example, computer and the internet) to teach English.

36. I know how to use different methods/techniques to add to my expertise and improve my teaching, for example doing reflection, journal writing, observation, etc.

37. I know how to design English tests/exams using a theoretical model that explains the nature of language proficiency, for example universal grammar theory, and theory of communicative competence. 38. I know how to design different types of exams/tests for my classes, for example multiple-choice tests, cloze passages, and essay-type exams.

39. I know how to develop grading systems for my exams/tests, for example how to weigh each exam/test components, and how to weigh each component vis-a-vis other components.

40. I know how to use multiple methods for assessing my students' achievement and/or progress, for example quizzes, tests, portfolios, and peer assessment.

41. I know how exams/tests affect teaching and learning, for example how I may teach for the exam, or how my students may channel their learning for the exam.

42. I know how to manage classroom time, that is how much time to allocate to different class activities and/or interactions.

43. I know how to monitor and respond to possible discipline threats to order in my classroom or throughout lessons, for example identifying disturbing behaviour(s), reprimanding, and regrouping students.

44. I know the rules and policies of the schools and/or institutions I work for, for example registration rules, exam regulations, and rules regarding student absenteeism.

45. I know the particular teaching/learning materials of the schools/ institutions I work for, e.g., their designated course books, and their learning materials such as dictionaries/software.

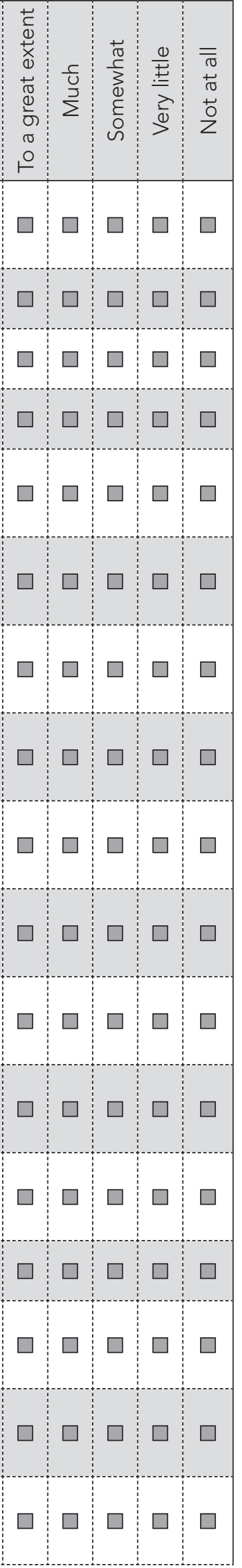




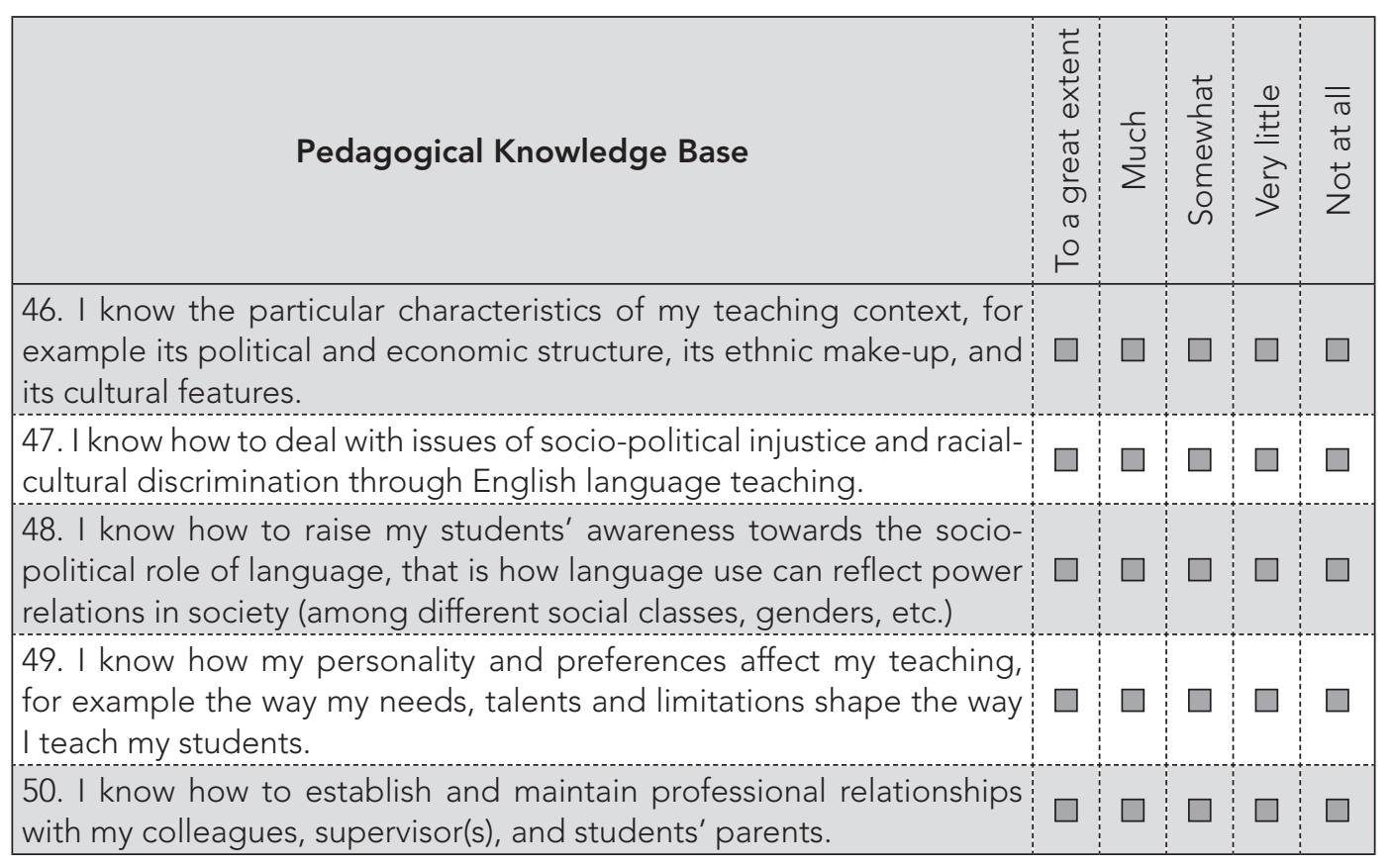

Figure 3: Self-assessment questionnaire of pedagogical knowledge

\section{Model evaluation}

Model evaluation was used after CFA to estimate the model's overall fit for the confirmatory dataset. Given that there is no single agreed upon criterion for model evaluation (Heubeck and Neill, 2000), heuristic measures called goodness of fit indices tests - including absolute fit, incremental fit, and parsimony fit - were conducted on the confirmatory dataset. In addition to normed chi-squared statistic, the analyses of this phase included absolute fit tests of the root mean square error of approximation (RMSEA) and the root mean square residual (RMR), incremental fit test of the nonnormed fit index (NNFI), and the parsimony fit goodness-of-fit index (PGFI), as well as the parsimonious normed fit index (PNFI).

In order to ensure that the final model adequately fits the data, the confirmatory dataset was used in model-fit analysis. As Table 3 shows, the assessment indices for absolute fit, incremental fit, and parsimony fit are all larger than the minimum cut-off values needed for appropriate model fit, that is, normed chi-squared $<2$, RMSEA $<$ $0.05, \mathrm{RMR} \approx 0, \mathrm{NNFI}>0.90, \mathrm{PGFI}>0.50$, and PNFI $>0.50$. These model-fit estimates, in turn, confirmed the validity of the model that emerged from the CDA phase of the study.

Table 3: Absolute, incremental and parsimony of fit indices for the confirmatory dataset

\begin{tabular}{|c|c|c|c|c|c|c|}
\hline \multirow{2}{*}{ Dataset } & \multicolumn{3}{|c|}{ Absolute fit } & \multirow{2}{*}{$\begin{array}{c}\text { Incremental fit } \\
\text { NNFI }\end{array}$} & \multicolumn{2}{|c|}{ Parsimony fit } \\
\hline & Chi-Sq/DF & RMSEA & RMR & & PGFI & PNFI \\
\hline Cut-off values & $<2$ & $<0.05$ & $\approx 0$ & $>0.90$ & $>0.50$ & $>0.50$ \\
\hline Confirmatory dataset & 1.60 & 0.049 & 0.078 & 0.91 & 0.65 & 0.70 \\
\hline
\end{tabular}




\section{Discussion and conclusion}

Learning to teach is a complex and lifelong process, so are the bodies of knowledge that teachers develop for their practices. Understanding what constitutes pedagogical knowledge, therefore, poses several ontological, epistemological and methodological questions about the nature of the thinking mind, the relationship between embodied, articulated and unarticulated forms of knowing, the ways in which personal biographies, time, space and activity interact in the ongoing (re)production of knowledge, and how one can best provide an account of pedagogical knowledge without reducing its personal and contextual complexities. The long tradition of teaching and teacher education research has tried to address these questions, albeit in a fragmented and often siloed fashion. This has resulted in a field of inquiry that houses multiple traditions, terms and labels.

In this study, we drew upon complex-system and lifelong-learning perspectives to propose and validate a conceptual framework for pedagogical knowledge focusing on the field of English language teaching. The model that emerged from our analyses explains pedagogical knowledge in terms of nine components: knowledge of subject matter; knowledge of teaching; knowledge of students; knowledge of classroom management; knowledge of educational context; knowledge of democracy, equity and diversity; knowledge of assessment/testing; knowledge of learning; and knowledge of (professional) self. Within this nine-factor framework, the components of pedagogical knowledge consist of 50 subcomponents that provide a detailed account of what each dimension of pedagogical knowledge entails.

In the absence of a validated model that can help explain pedagogical knowledge (Akbari and Dadvand, 2014), the findings of this study can have conceptual and practical implications for teaching and teacher education research. At a theoretical level, a validated model that frames pedagogical knowledge through its constitutive elements can provide more conceptual coherence to an area of teacher education research that is characterized by multiple, and at times seemingly contradictory, terms and labels. At a more practical level, such a framework can help bridge the theorypractice divide in teacher education research by offering an evidence-informed basis for a range of decisions regarding teacher admission, preparation and certification in teacher education programmes.

We should note at the end that caution needs to be exercised in interpreting and applying the findings of this study. As a complex system, pedagogical knowledge represents a dynamic and context-sensitive system of mutually constituting elements that evolve over time and in response to the particularities of teaching contexts. Therefore, the boundaries we have constructed among different components and subcomponents of pedagogical knowledge should be understood as serving an analytical-conceptual purpose. As housed within a complex system, these territories of knowledge remain fluid, without discernable beginnings or endings. Far from being a finished product, pedagogical knowledge remains in a constant state of flux throughout life, with multiple personal, institutional, social, cultural and political factors contributing to it.

This points to the context-specificity of pedagogical knowledge. What constitutes relevant or viable teaching knowledge may vary depending on the needs and circumstances that surround teachers' work within different settings. In agreeing with Burns et al. (2015), who have pointed to the impacts of socio-historical factors within the classroom on teachers' cognition, we wish to underline the importance of context, temporality and spatiality in teaching and the sorts of knowledge it requires. 
Therefore, we reiterate that our proposed framework is not meant as a one-size-fits-all template. Rather, it aims to further enhance our understanding of the complexities of teaching as a form of professional practice, which is guided, among other things, by significant bodies of pedagogical knowledge (Shulman, 1998).

\section{Notes on the contributors}

Babak Dadvand is a research fellow and lecturer at the Melbourne Graduate School of Education, the University of Melbourne. Babak's research is in the areas of teaching and teacher education, diversity, equity and social justice education, as well as civics and citizenship education.

Foad Behzadpoor is a lecturer at Azad University, West Tehran Branch, Iran. Foad's research focuses on teacher education, reflective teaching, second language acquisition and English for specific purposes (ESP).

\section{References}

Akbari, R. and Dadvand, B. (2011) 'Does formal teacher education make a difference? A comparison of pedagogical thought units of BA versus MA teachers'. Modern Language Journal, 95 (1), 44-60.

Akbari, R. and Dadvand, B. (2014) 'Pedagogical knowledge base: A conceptual framework for teacher admission'. System, 42, 12-22.

Akbari, R. and Tajik, L. (2012) 'Second-language teachers' moral knowledge base: A comparison between experienced and less experienced, male and female practitioners'. Journal of Moral Education, 41 (1), 39-59.

Andrews, S. and Svalberg, A.M.-L. (2016) 'Teacher language awareness'. In Cenoz, J., Gorter, D. and May, S. (eds) Language Awareness and Multilingualism. Cham: Springer, 1-13. Online. https://tinyurl.com/vhpb6bh (accessed 24 November 2019).

Baker, A. (2014) 'Exploring teachers' knowledge of second language pronunciation techniques: Teacher cognitions, observed classroom practices, and student perceptions'. TESOL Quarterly, 48 (1), 136-63.

Bauml, M. (2009) 'Examining the unexpected sophistication of preservice teachers' beliefs about the relational dimensions of teaching'. Teaching and Teacher Education, 25 (6), 902-8.

Ben-Peretz, M. (2011) 'Teacher knowledge: What is it? How do we uncover it? What are its implications for schooling?'. Teaching and Teacher Education, 27 (1), 3-9.

Borg, S. (2003) 'Teacher cognition in language teaching: A review of research on what language teachers think, know, believe, and do'. Language Teaching, 36 (2), 81-109.

Buehl, M.M. and Fives, H. (2016) 'The role of epistemic cognition in teacher learning and praxis'. In Greene, J.A., Sandoval, W.A. and Bråten, I. (eds) Handbook of Epistemic Cognition. New York: Routledge, 247-64.

Burns, A., Freeman, D. and Edwards, E. (2015) 'Theorizing and studying the language-teaching mind: Mapping research on language teacher cognition'. Modern Language Journal, 99 (3), 585-601.

Clandinin, D.J. (1986) Classroom Practice: Teacher images in action. London: Falmer Press.

Cochran-Smith, M. and Villegas, A.M. (2015) 'Framing teacher preparation research: An overview of the field - Part 1'. Journal of Teacher Education, 66 (1), 7-20.

Darling-Hammond, L. and Bransford, J. (eds) (2005) Preparing Teachers for a Changing World: What teachers should learn and be able to do. San Francisco: Jossey-Bass.

Dörnyei, Z. (2003) Questionnaires in Second Language Research: Construction, administration, and processing. Mahwah, NJ: Lawrence Erlbaum Associates.

Elbaz, F. (1983) Teacher Thinking: A study of practical knowledge. London: Croom Helm.

Farrell, T.S.C. and Lim, P.C.P. (2005) 'Conceptions of grammar teaching: A case study of teachers' beliefs and classroom practices'. TESL-EJ, 9 (2), 1-13.

Feryok, A. (2010) 'Language teacher cognitions: Complex dynamic systems?'. System, 38 (2), 272-9.

Fisher, L. (2009) 'Trainee teachers' perceptions of the use of digital technology in the languages classroom'. In Evans, M.J. (ed.) Foreign-Language Learning with Digital Technology. London: Continuum, 60-79. 
Gatbonton, E. (2000) 'Investigating experienced ESL teachers' pedagogical knowledge'. Canadian Modern Language Review, 56 (4), 585-616.

Golombek, P.R. (1998) 'A study of language teachers' personal practical knowledge'. TESOL Quarterly, 32 (3), 447-64.

Hayes, D. (2010) 'Duty and service: Life and career of a Tamil teacher of English in Sri Lanka'. TESOL Quarterly, 44 (1), 58-83.

Heubeck, B.G. and Neill, J.T. (2000) 'Internal validity and reliability of the 30 item mental health inventory for Australian adolescents'. Psychological Reports, 87, 431-40.

Hillier, Y. (2005) Reflective Teaching in Further and Adult Education. 2nd ed. London: Continuum.

Inbar-Lourie, O. (2008) 'Constructing a language assessment knowledge base: A focus on language assessment courses'. Language Testing, 25 (3), 385-402.

Jakeman, A.J., Letcher, R.A. and Norton, J.P. (2006) 'Ten iterative steps in development and evaluation of environmental models'. Environmental Modelling and Software, 21 (5), 602-14.

Johnson, K.E. (2009) Second Language Teacher Education: A sociocultural perspective. New York: Routledge.

Kiss, T. (2012) 'The complexity of teacher learning: Reflection as a complex dynamic system'. Journal of Interdisciplinary Research in Education, 2 (1), 17-35.

Korthagen, F. (2017) 'Inconvenient truths about teacher learning: Towards professional development 3.0'. Teachers and Teaching: Theory and Practice, 23 (4), 387-405.

Lee, I. (2010) 'Writing teacher education and teacher learning: Testimonies of four EFL teachers'. Journal of Second Language Writing, 19 (3), 143-57.

Liu, H., Lin, C.-H., Zhang, D. and Zheng, B. (2017) 'Language teachers' perceptions of external and internal factors in their instructional (non-) use of technology'. In Lin, C.-H., Zhang, D. and Zheng, B. (eds) Preparing Foreign Language Teachers for Next-Generation Education. Hershey, PA: Information Science Reference, 56-73.

Loewenberg Ball, D., Hoover Thames, M. and Phelps, G. (2008) 'Content knowledge for teaching: What makes it special?'. Journal of Teacher Education, 59 (5), 389-407.

Lortie, D.C. (1975) Schoolteacher: A sociological study. Chicago: University of Chicago Press.

McKay, S.L. (2003) 'Toward an appropriate EIL pedagogy: Re-examining common ELT assumptions'. International Journal of Applied Linguistics, 13 (1), 1-22.

McNamara, T. (2005) 'Second language testing and assessment: Introduction'. In Hinkel, E. (ed.) Handbook of Research in Second Language Teaching and Learning. Mahwah, NJ: Lawrence Erlbaum Associates, 775-8.

Mori, R. (2011) 'Teacher cognition in corrective feedback in Japan'. System, 39 (4), 451-67.

Mulcahy, D. (2012) 'Affective assemblages: Body matters in the pedagogic practices of contemporary school classrooms'. Pedagogy, Culture and Society, 20 (1), 9-27.

Mullock, B. (2006) 'The pedagogical knowledge base of four TESOL teachers'. Modern Language Journal, 90 (1), 48-66.

Myers, J.P. (2009) 'Learning in politics: Teachers' political experiences as a pedagogical resource'. International Journal of Educational Research, 48 (1), 30-9.

Opfer, V.D. and Pedder, D. (2011) 'Conceptualizing teacher professional learning'. Review of Educational Research, 81 (3), 376-407.

Osam, U.V. and Balbay, S. (2004) 'Investigating the decision-making skills of cooperating teachers and student teachers of English in a Turkish context'. Teaching and Teacher Education, 20 (7), 745-58.

Pollard, A. (2005) Reflective Teaching. 2nd ed. London: Continuum.

Reeves, J. (2009) 'A sociocultural perspective on ESOL teachers' linguistic knowledge for teaching'. Linguistics and Education, 20 (2), 109-25.

Richards, J.C. (1996) 'Teachers' maxims in language teaching'. TESOL Quarterly, 30 (2), 281-96.

Schwille, J., Dembélé, M. and Schubert, J. (2007) Global Perspectives on Teacher Learning: Improving policy and practice. Paris: United Nations Educational, Scientific and Cultural Organization.

Sharma, S. (1996) Applied Multivariate Techniques. New York: Wiley.

Shulman, L.S. (1986) 'Those who understand: Knowledge growth in teaching'. Educational Researcher, 15 (2), 4-14.

Shulman, L.S. (1998) 'Theory, practice, and the education of professionals'. Elementary School Journal, 98 (5), 511-26.

Shultz, K.S. and Whitney, D.J. (2005) Measurement Theory in Action: Case studies and exercises. Thousand Oaks, CA: SAGE Publications. 
Su, Y., Feng, L. and Hsu, C.-H. (2018) 'What influences teachers' commitment to a lifelong professional development programme? Reflections on teachers' perceptions'. International Journal of Lifelong Education, 37 (2), 184-98.

Svalberg, A.M.-L. (2015) 'Understanding the complex processes in developing student teachers' knowledge about grammar'. Modern Language Journal, 99 (3), 529-45.

Tsang, W.K. (2004) 'Teachers' personal practical knowledge and interactive decisions'. Language Teaching Research, 8 (2), 163-98.

Verloop, N., Van Driel, J. and Meijer, P. (2001) 'Teacher knowledge and the knowledge base of teaching'. International Journal of Educational Research, 35 (5), 441-61.

Walberg, H.J. (1977) 'Decision and perception: New constructs for research on teaching effects'. Cambridge Journal of Education, 7 (1), 33-9.

Watzke, J.L. (2007) 'Foreign language pedagogical knowledge: Toward a developmental theory of beginning teacher practices'. Modern Language Journal, 91 (1), 63-82.

Woods, D. and Çakır, H. (2011) 'Two dimensions of teacher knowledge: The case of communicative language teaching'. System, 39 (3), 381-90.

Yoshida, R. (2010) 'How do teachers and learners perceive corrective feedback in the Japanese language classroom?'. Modern Language Journal, 94 (2), 293-314.

Zheng, H. (2013) 'Teachers' beliefs and practices: A dynamic and complex relationship'. Asia-Pacific Journal of Teacher Education, 41 (3), 331-43.

Zheng, H. (2015) Teacher Beliefs as a Complex System: English language teachers in China. Cham: Springer. 